\title{
"Characters in Search of an Author". Human figures and storytelling in architectural design communication
}

\author{
Fabio Colonnese ${ }^{1}$ \\ ${ }^{1}$ Sapienza University, Dept. of History, Drawing, and Restoration of Architecture, 00186 Rome, Italy
}

\begin{abstract}
In a presentation drawing, human figures have a natural attitude to work as an optical reference to measure the design space and to provide a sort of instructions to use it, but over the centuries, their agency has been multifaceted. The practice of photo-collages, which was fed by photography and cinema development, has recently spread thank to the digital techniques and human figures in architecture renderings seem to have become as fundamental as a top-modes for a fashion magazine cover. Besides providing a recognizable mark to the design entry, selecting peculiar figures can visually connect a design to a specific place and time, working as a cultural, situationist and sensorial agent. This seems to be true particularly for the cultural typologies. In renderings of museums, theatres or libraries, often ordinary people are integrated by figures of artworks and celebrities, like in Alberto Campo Baeza and Raphael Gabrion's design for a Louvre new building in Lievin, France, whose figures are placed in the renderings not only to explain the functions but also to remind the ambiguous threshold between representation and reality.
\end{abstract}

\section{Introduction}

In the context of the digital production by "CAD monkeys, rendering farms, and outsourcers", hyper-rendered seductive scenes look often detached from real people and places [1]. An architectural "scene" is commonly intended as a mere picture of an imagined place for commercial goals, while it can also take into account the social context and agenda to depict a theatrical "scene", in which "action is carried on, business is being done, or events are happening" [2]. This specific attitude is currently practiced by those architectural visualizers who use to portray designed buildings immersed in peculiar environments, at night, under the rain falling or half-hidden in the mist. The people inhabiting the picture, whose agency seems to have become more and more central in any architectural communication, exploit much of the potential narrative of an architectural "scene". This seems to be particularly important for the culture-addressed typologies such as museums, theatres or libraries. Here, the diffusion of digital photo-collage in the renderings gives the architects the possibility to integrate figures of ordinary people with those of celebrities, artists and artworks, amplifying the ambiguity implicit in every visual representation and questioning the relationship between art and architecture. The analysis of the 2015 
competition entry for the Louvre new building in Liévin by Alberto Campo Baeza and Raphael Gabrion provides the opportunity to frame and discuss the current development of human figures in the communication of architectural designs. In particular, the analysis of the digital renderings by disassembling the visual components and individuating the source of some of the human figures and artworks shown, compared with the specific quality of the proposed building, reveals not only the central role of figures in denoting it as a Louvrerelated museum and the activities planned inside it, but also a critical approach toward the museum as institution, the relationship between true and fake, and the fragile boundary between virtual and real.

\section{Human figures in architectural drawings}

Renaissance architects used to associate the human body to architectural orders and overlaid it to church plans and palace facades to demonstrate the proportional relationship between human and architectural body [3]. Instead, "conceptions of the body of modern architects have their roots in the post-Galilean view, which conceives of the physical body as a machine and as a subject of mechanical laws" [4]. In particular, between the $19^{\text {th }}$ and $20^{\text {th }}$ century, the human body was gradually reduced to a series of physical parameters and performances to optimize production pipelines, machines, and urban spaces, generally idealizing movements and behaviours according to Taylorism. From half of last century, the presence of human figures in architectural drawings is being interpreted as symptom of a particular sensibility toward human scale and needs, not only according to the kinds of representation but to the different ideas on men and women.
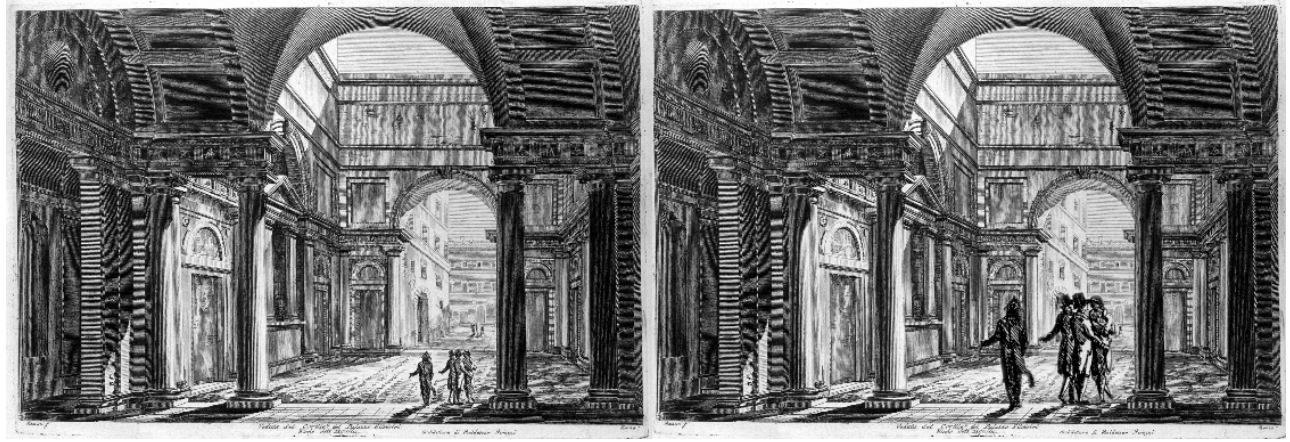

Fig. 1. Luigi Rossini, Veduta del Cortile di Palazzo Silvestri, $1818 \mathrm{ca}$. On the left, the original print; on the right, a photomontage showing the actual size of people compared to building's size (Museo di Roma, MR23670; Elaboration by the author).

Human figures are conventionally used in architectural drawings as an optical reference to visually express the scale and size of design space, [5] like "scalies", as suggested by Waverly Lowell [6]. In contrast, they can be used to deceive the actual size of either a real place, like the little courtyard of the Palazzo Silvestri in Rome drawn by Piranesi's follower Luigi Rossini, or imagined spaces, like in artfully oversized perspective views of Boullée's metropolitan church. In this role, human figures may either look as consistent as the architecture is, like the black shadows drafted by Mies van de Rohe [7], or even become grey or transparent silhouettes to better reveal the buildings behind them.

Human figures may affect the reception of an architectural scene by contributing to defining its spatial and temporal context, but they are also used to provide the readers with further information on either the represented architecture or its designer's ideas. For example, 
they can provide a sort of instructions-to-use the design space or some of its components: an attitude inversely proportional to their graphic definition and detail, as the more a figure is detailed, the more it suggests an additional fictive role in the drawing and engage reader's body. Think of Le Corbusier's domestic interiors inhabited by people acting, reading, painting, cooking or playing, in order to describe the potentials of modern housing and to offer the viewer a new way of living with an unconventional sense of freedom. Somehow, Le Corbusier used people not only to explain his unconventional spaces but also to promoting and "marketing an aspirational lifestyle" [8].
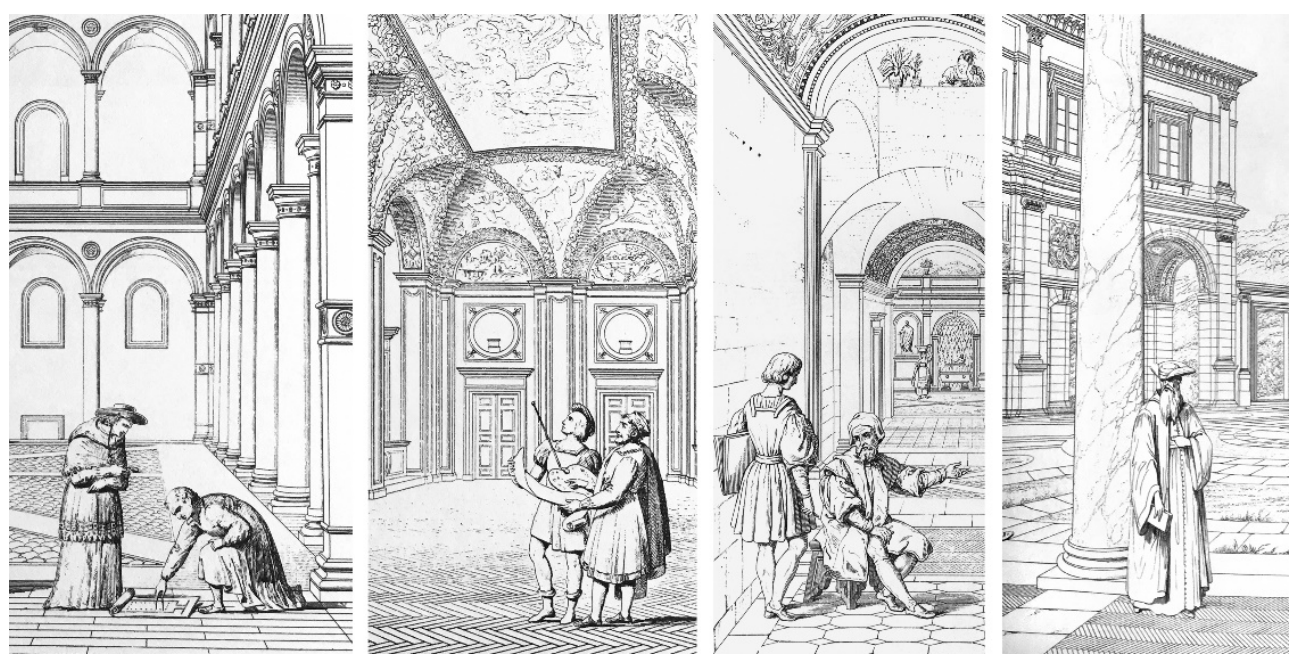

Fig. 2. Bramante consulting a plan in the courtyard of Palazzo della Cancelleria; Baldassarre Peruzzi and Raphael observing the frescoes in the Villa Farnesina; Michelangelo inviting Raphael in his own house; Vignola in Villa Giulia's courtyard. From Paul-Marie Letarouilly, Edifices de Rome Moderne, 1868-74 (Elaboration by the author).

In the fundamental Edifices de Rome Moderne, Paul-Marie Letarouilly used to add the figures of the Renaissance architects he supposed to have designed the palaces and villas he had surveyed, "corrected" and illustrated. The figures of Bramante, Baldassarre Peruzzi, Raphael, Vignola or Michelangelo are not only measuring the space and reminding the designer, but also legitimizing the rectifications Letarouilly made on the effective building surveys to restore their original form, at least according to his own idea. Quite on the same wake, a century later, the American architect Richard Meier cut-and-pasted Karl Friedrich Schinkel's trees and copied Otto Wagner's old-fashioned figures to provide an historical environment to his museum designs [9]. While these apparent contradictions can be easily accepted in an architectural survey, they look bizarre in the rendering of an architectural design, which is expected to show an anticipation of an upcoming transformation. The existence of elements contesting the space-temporal reality of the design are used to make the beholder formulate conjectures about them, adding a mental dimension to the mere visual fruition of the picture. Although the final visual effect of the rendering can be quant or perturbing, those anachronistic elements may help the design be recognizable, distinguished and memorised by the commission of a competition.

\section{From Manual to Digital Photo-montage}

Adding people to an architectural scene requires a certain compatibility between the characteristics of the single figure (pose, clothes, light-and-shade) and that of the space representation (point of view, surfaces rendering, colors, shadows, etc.). Architecture 
visualizers can take staged perfect people from one of the several on-line digital photography stacks or can do it by themselves, by cutting-and-pasting figures of their own friends or other real people doing real things. Of course, one can also choose peculiar people, such as politics, celebrities, artists and even fantastic characters in order to convey specific meanings or political agendas [10]. In the early decades of the $20^{\text {th }}$ century, when the practice of collage and photomontage spread, the photographs available, often offered by a few fashion magazines, were scarce and their fixed size strongly constrained their use in a perspective view, contributing to the surreal and subversive effects that have made the collages of Max Ernst or Bruno Munari famous.

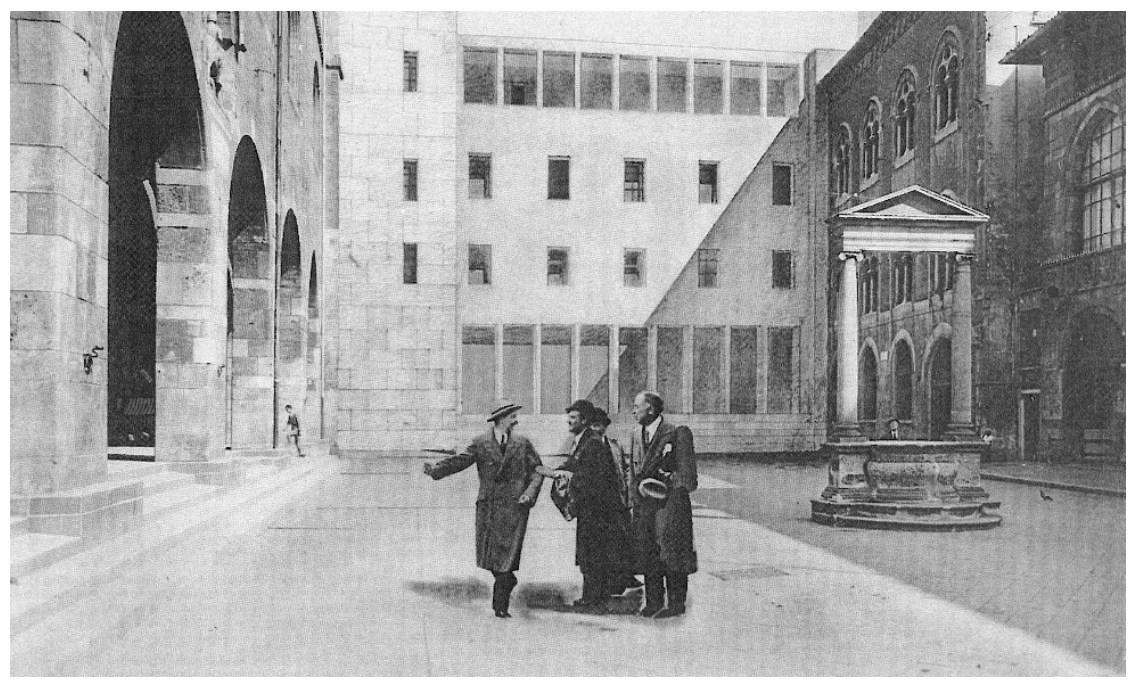

Fig. 3. P. Bottoni, G.L. Giordani, M. Pucci, Design of Piazza del Duomo in Milan, 1937, Photoreproduction detail of the perspective photomontage (Milan, Politecnico di Milano, DAStU, Archivio Piero Bottoni, op.155, Photographs, 18).

Inspired by early photography artists as well as graphic designers, architects began to enrich their drawings with photo-collage treatments, often with original consequences. Since 1930s, the Italian architect Piero Bottoni, one of the pioneers of this technique, has applied the cinematic practice of self-cameo, which was pioneered by Alfred Hitchcock, in his perspective photomontages, revealing how the growing influence of photography and cinema enhanced the fictive role of human figures in presenting architecture [11]. In general, the use of photographic figures in collage-drawings has the potential consequence of both relating the picture to other places and times and of including extra-architectural narratives useful to convey artistic, political, and social meanings, especially when figures of recognizable people are pasted. In the 1952 project for the Golden Lane reconstruction in East London, Alison and Peter Smithson cut-and-pasted the photographic figures of cinema and sport celebrities like Gerard Philipe, Claude Autant-Lara, Peter Ustinov, Marylin Monroe and Jo di Maggio onto their renderings, to express the subversive and ground-breaking character of their housing design and, at the same time, to superimpose a sort of new "as-found" reality [12].

After the political peak of architectural photomontages by Archigram and Superstudio in early 1970s, the advent of Xerox machines and then of digital technologies removed the aforementioned operational limits and today copying, cutting, adapting - in terms of size and colour - and pasting a figure taken from the internet massive archive into any digital rendering is easy, fast and for everyone equipped with a Photoshop-like software. At the same 
time, human figures in architectural renderings seem to have become as fundamental as topmodels for a fashion magazine cover.

\section{Figures in the Museum}

Designing a museum is always dealing with the concepts of art and social institution, especially in the classical wake of architecture as a synthesis of the arts. Already Schinkel's perspective view of the main staircase gallery of Alte Museum in Berlin shows human figures "captured at the moment of being amazed by the paintings or immersed in a conversation while walking through the museum, act as characters in a montage that unleashes the imagination of the spectator." [13].

From the second half of $20^{\text {th }}$ century onwards, architects such as James Stirling or Mansilla+Tunon took the habit of adding peculiar figures in the renderings of their museum designs. For example, the rooms and garden of Thyssen-Bornemisza Museum Stirling designed in 1987 are haunted by British artists Gilbert \& George, De Chirico's silent muses and renaissance artists with their young apprentices, while black-and-white photographic figures of artists like Le Corbusier and Joseph Beuys appear like tutelar deities in most of Mansilla+Tunon's renderings [14]. At the same time, the photographic images of artworks can be directly reproduced in the renderings, even when they are made with manual techniques, as can be seen in Steven Holl's watercolour views for the Swiss Embassy Gallery in Washington, DC.

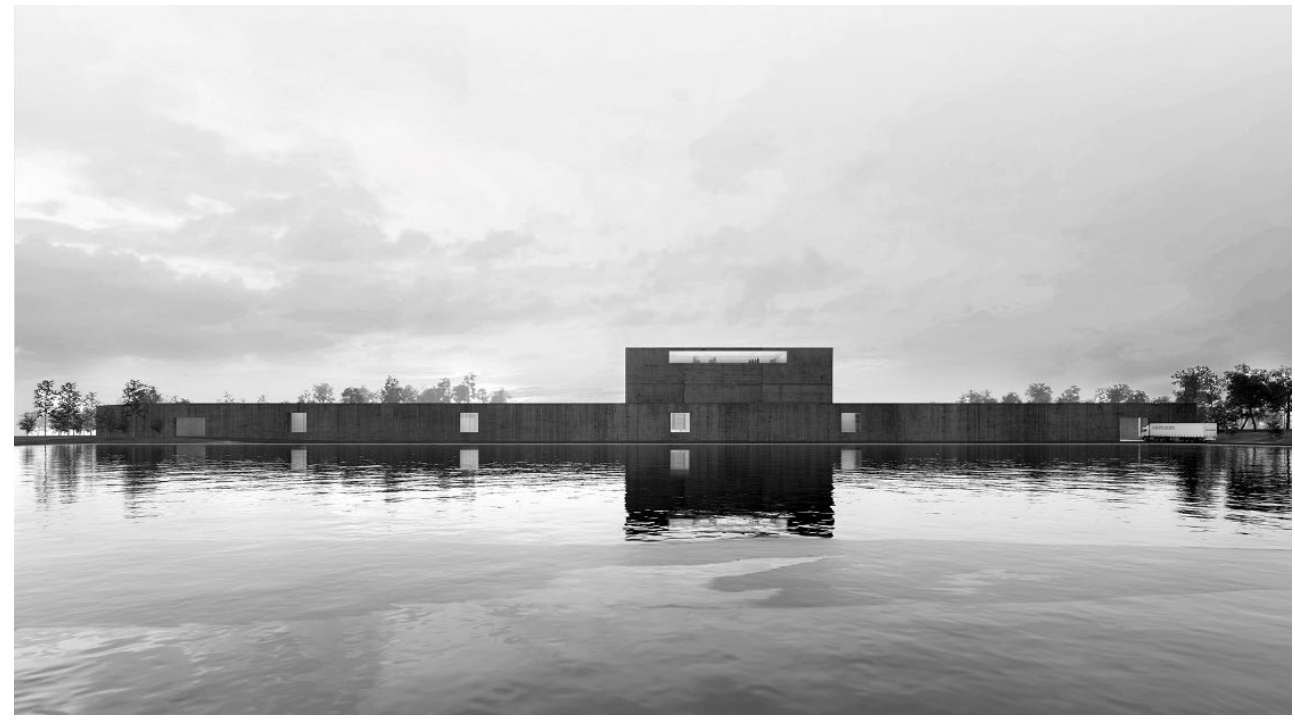

Fig. 4. Alberto Campo Baeza and Raphael Gabrion, Conservation and Storage Facility for the Louvre Museum in Liévin, 2015. Digital rendering of the building (Courtesy of Alberto Campo Baeza and Raphael Gabrion).

\subsection{Campo Baeza and Gabrion's design of Louvre}

In 2015, the Spanish architect Alberto Campo Baeza and the French architect Raphael Gabrion have proposed a further innovative step in this kind of architecture presentation. Together with Elena Jiménez, Tommaso Campiotti, María Pérez de Camino, Imanol Iparraguirre, Ignacio Aguirre, Alejandro Cervilla, as well as Raphaël Gabrion's collaborators 
in Paris, they have designed a rectangular building for the Conservation and Storage Facility for the Louvre Museum in Liévin, in an area in which two sturdy coal chimney stacks still mark the memory of a previous anthracite mining centre. The building is described as " $\mathrm{A}$ large, dark podium housing all the workshops and services, with the cubic part of this great warehouse emerging like the chimney of a great boat" [15]. Such a metaphorical reading is suggested by their motto bateau ivre (the drunken boat), echoing the title of the well-known Rimbaud poem and working as a primary metatext.

The project is presented by a number of different drawings and pictures: plans, sections, pictures after a maquette, exploded axonometric view and perspective section after a digital model, and no less than 15 black-and-white renderings: seven outdoor and eight indoor views. Conceived as a concrete cubic storage crowned by offices and laboratories around narrow patios, the building looks like neither a building dedicated to art nor an artwork in itself. Besides a huge fenetre-en-longueur looking onto the coal pyramids, the renderings show the rooms are quite neutral, characterized by indirect light provided by the closed courtyards and a high sky-light. In the architectural context, most of the explaination of functional goal of spaces is trusted on the figures pasted onto the views.

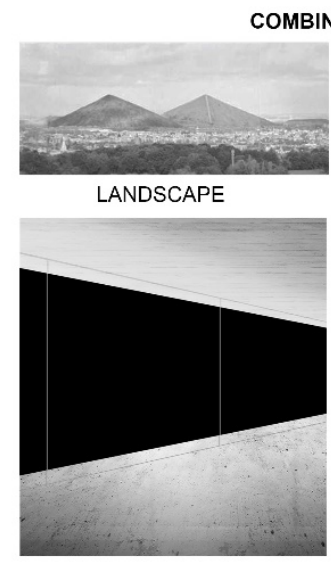

ARCHITECTURE

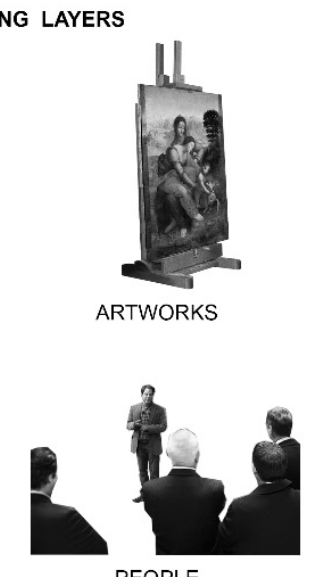

PEOPLE

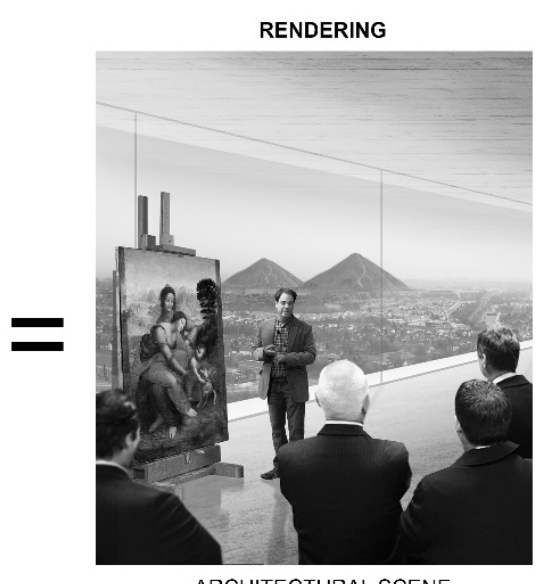

ARCHITECTURAL SCENE

Fig. 5. Alberto Campo Baeza and Raphael Gabrion, Conservation and Storage Facility for the Louvre Museum in Liévin, 2015. Digital rendering decomposed in main layers (Courtesy of Campo Baeza and Gabrion; elaboration by the author).

\subsection{Artworks and Figures}

Figures of artworks constitute a first category of visual elements denoting the building as a cultural institution. Moreover, the sculpture known as The Marly Horse or Eugène Delacroix's La Liberté guidant le peuple are commonly relatable to the Louvre, with Hubert Robert's La Grande Galerie directly showing its interior rooms. The figures of people looking at, moving or working on the artworks constitute a second category of visual elements identifying the museum as a place for ordering, conserving, restoring and exhibiting pieces. Some of them are not generic figures, like tourists and visitors looking at works, maybe taken in the rooms of Louvre itself, but specific figures. For example, a group of them is presumed to be pasted from a screenshot of Stan Neumann's Leonardo da Vinci: The Restoration of the Century, a documentary presenting the restoration of Leonardo's St Anna and the Vergin made between 2010 and 2012. 
The rendering of the main entrance to the building shows a larger figure pasted on the right, absently welcoming the beholder. It is clearly recognizable as the Italian Neorealism director Vittorio De Sica who seems to have been chosen for some specific reason. The figure has been cut out of a 1950s picture taken in London and recently shown in the exhibition Tutti De Sica [16]. He might suggest an intimate relationship with the Pantheon, which Campo Baeza is very fond of, for a sequence of his 1952 movie Umberto D. was shot outside the monument and its light oculus is quoted in the Louvre design sketches, too. Eventually, De Sica could somehow validate the black-and-white quality of the renderings and convey both the idea of fiction, which is implicit in every representation, and the condemnation of the current trend of spectacularizing museum space.

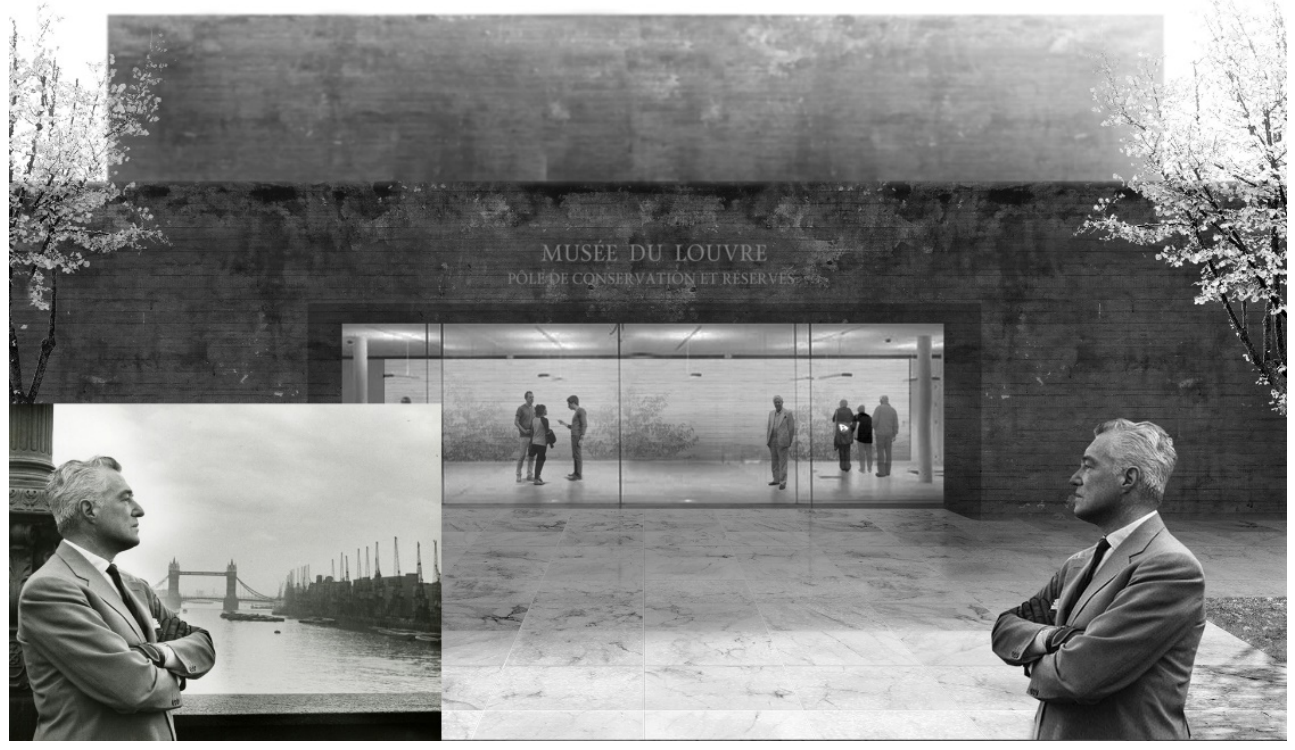

Fig. 6. Alberto Campo Baeza and Raphael Gabrion, Conservation and Storage Facility for the Louvre Museum in Liévin, 2015. Digital rendering of the main entrance with Vittorio De Sica cut, mirrored and pasted from the 1950s picture on the left (Courtesy of Campo Baeza and Gabrion).

In the rendering of the "large format unpacking area," the sculptures and potteries among the wooden boxes are looked at by an elegant man seen from behind, which has been cut out of a screenshot of Giuseppe Tornatore's La migliore offerta, a movie released in 2013. The figure shows the Australian actor Geoffrey Rush as Virgil Oldman, a standoffish and aloof art auctioneer. Together with his friend and painter Billy, Virgil uses his expertise in forgery to manipulate the mind of the bidders and acquire artworks at a very low price. The figure is taken from the sequence in which he is revealing his secret collection of woman portraits to his beloved Claire, a fragile lady apparently affected by agoraphobia he had known for business but eventually revealing to be a member of thievery plan organized to steal Virgil's priceless collection. On the first impression, the figure of Virgil could simply recall the visual seduction of art as well as the excesses and risks of its trading, but there something more. The concepts of fake and authentic are central in the whole movie, as testified by the following passage:

"- Claire: In an old article of yours I found on the internet, you said: There's something authentic in every forgery. What did you mean?"

“- Virgil Oldman: When simulating another's work the forger can't resist the temptation to put in something of himself. Often, it's just a trifle, a detail of no interest. One unsuspected 
stroke, by which the forger inevitably ends up betraying himself, and revealing his own utterly authentic sensibilities".

This dialogue casts a different light on the story and the rendering itself. It reminds that every fiction, like an architecture scene apparently designed to sell a building, hides something deeply real and the figures chosen to inhabit the scene are likely to be that detail from the real life betraying the author and declaring his or her true intentions.
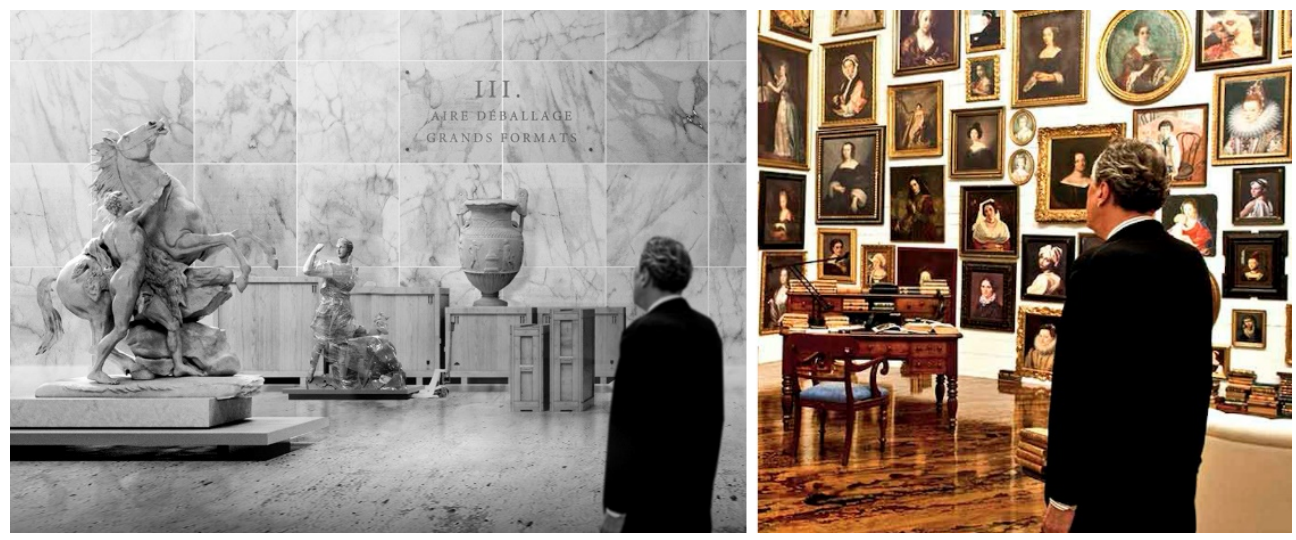

Fig. 7. Alberto Campo Baeza and Raphael Gabrion, Conservation and Storage Facility for the Louvre Museum in Liévin, 2015. Digital rendering with Geoffrey Rush from La migliore offerta, compared with the movie original shot on the right (Courtesy of Campo Baeza and Gabrion).

\subsection{Representations of Representations}

A third category of visual products denoting the building as a cultural institution is established by three supplementary photomontages conceived as "postcard images". More than just renderings, they show the museum design inserted into the background of JeanFrançois Millet's L'Angélus, Claude Monet's Soleil Levant and as a model onto the table of Jean-Baptiste-Siméon Chardin's L'Enfant au toton. All of them being property of Louvre, they constitute an original way of presenting a museum design by providing a sort of shortcircuit between container - the museum - and content - the work.

Despite Leon Battista Alberti's and Raphael's condemnation of perspective views in architecture design communication, the use of painting is a long-term consolidated practice, from Hubert Robert and John Soane to Zaha Hadid and Pezo von Ellrichshausen, or the Italian architect Giancarlo Rosa, whose competition entries are usually presented by a De Chirico-like painting by his wife and artist Maria Carla Savi [17]. Nevertheless, Campo Baeza and Gabrion's postcards are something different. They are neither architecture renderings with special figures pasted onto nor paintings made on purpose for illustrating an architectural design but existing paintings turned into architecture design presentations. It is no more the human figure that contextualize the project but the project image that recontextualize the figures and the whole painting, parasitizing their story-telling and unlocking it to new meanings.

The intervention on L'Angélus has involved some propaedeutic alterations of the work. For example, the higher part of the sky with some ducks flying has been cut away and a wider distance has been created between the two figures in the foreground in order to better fit the building shape in the background as well the two pyramids of coal taken from a photograph. 
Quite the same building shape has been placed in the upper part of Soleil Levant (it is quite difficult to speak of perspective or depth here) and textured with impressionistic brushstrokes captured from the painting itself, finally removing also the artist's signature.

The intervention on Chardin's L'Enfant au toton is by far the most interesting of all. Here, the design is presented in form of a little dark-grey model onto a desk replacing the spinning top the boy was playing with. This montage causes several consequences on the design reception. First of all, the model is connoted as a game in itself, a sort of innocent boardgame or mysterious mathematical box explored by the boy's right hand. Second, this is no more a building in a landscape painted onto a canvas but a representation of a building into a room painted onto a canvas, furtherly mediating the sense of the picture and deceiving any clear boundary between reality and representation. Third, the spinning top removed cannot but recall Christopher Nolan's Inception. As known, in the movie released in 2010, Leonardo Di Caprio's character Cobb used a similar tool to understand if he was currently living in a dream or in the reality. Once again, this missing detail in the "postcard" could be a cinematic suggestion reminding that this picture is just a fiction, a sort of virtual reality with several levels of meaning but, at the same time, that it can be as important as the reality is.
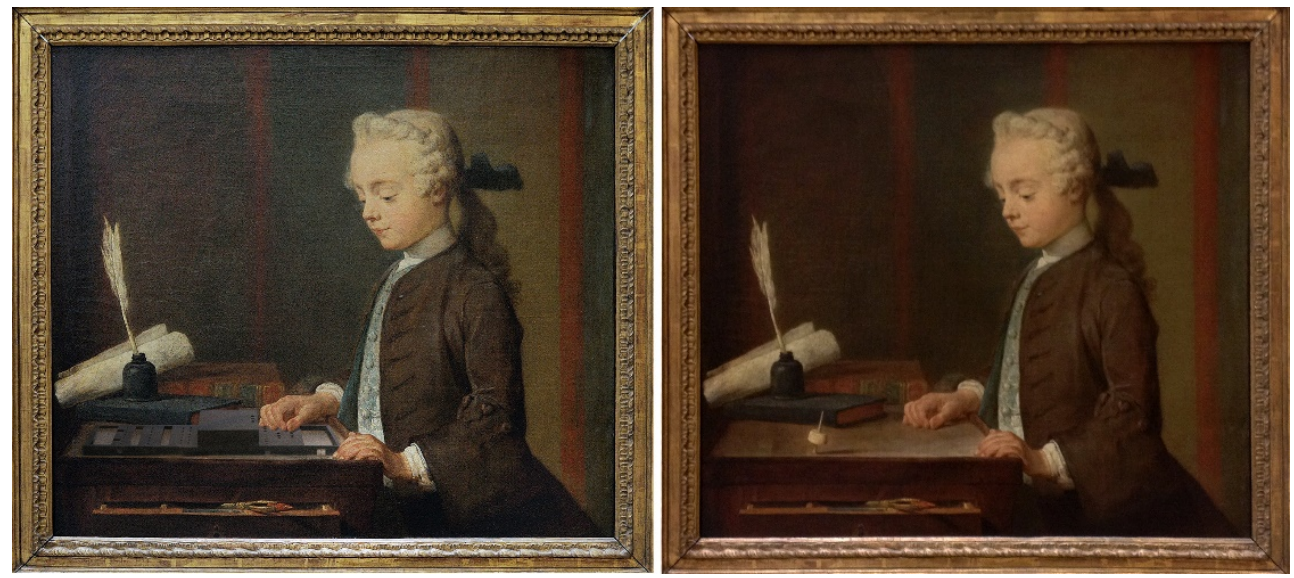

Fig. 8. Alberto Campo Baeza and Raphael Gabrion, Conservation and Storage Facility for the Louvre Museum in Liévin, 2015. Digital rendering of the building pasted onto Jean-Baptiste-Siméon Chardin's L'Enfant au toton compared with the original work at right (Courtesy of Alberto Campo Baeza and Raphael Gabrion).

\section{Conclusion}

In the context of the massive production of anonymous renderings generously worldwide spread by internet, selecting peculiar figures may result an antidote against the impending process of homologation and provide an opportunity to orchestrate the architectural scene according to a sort of secret plot. This strategy can be used also to connect the design to a specific place and time, working as a cultural, situationist and sensorial agent, or to deny it, by perturbing the design space with anachronistic elements that require a conjectural extrawork, like an open work waiting for the reader's collaborative interpretation.

The analysis of the renderings of Alberto Campo Baeza and Raphael Gabrion's design of the Conservation and Storage Facility for the Louvre Museum in Liévin, resulted in a differentiated use of human figures and artworks in relationship with their perception by the beholder: 
1. Measuring figures, dedicated to express the size of design space;

2. Functional figures, dedicated to express the activities of design space, here connected with the presence of artworks;

3. Fashioned figures, dedicated to contextualize the design in a specific place and age;

4. Recognizable figures, dedicated to provide cultural and social sense to design space, calling for subjective interpretations in the effort of deciphering the hypothetical intent of the designer. This effect is particular evident and layered when these "celebrities" are either involved in the visual arts or imagined characters from literature or cinema, for instance.

The three "postcard images" are an innovative format to present an architectural design that appears to fit perfectly the topic of the museum but would probably be inappropriate with other architectural typologies. They are also a litmus test of the opportunities offered today by the technique of digital collage in mixing-up and deceiving visual products from different sources, eventually contributing in tearing down every traditional wall between different artistic expressions and challenging any division between representation and reality. 


\section{References}

1. B. McGrath, C.-L. Hsueh, P.C. Hoi Shan, Rendering the Social in the Architectural Scene: Digital Representation and Social Inclusion on Architectural Design, Thinking, and Education. AMPS, 8, 4 (2016), p. 1

2. McGrath, Hsueh, Hoi Shan, Rendering the Social, p. 1

3. M. Frascari, The body and architecture in the drawings of Carlo Scarpa. Res, 14 (1987), pp. 123-142

4. R. Imrie, Architects' Conceptions of the Human Body, Environment and Planning. D: Society and Space, 21, 1 (2003), p. 47

5. A.T. Anderson, On the Human Figure in Architectural Representation. JAE, 55, 4 (2002), pp. $238-246$

6. Designing People, 2015 exhibition at the Environmental Design Archives at the University of California Berkeley. Https://archives.ced.berkeley.edu/blog/upcoming-exhibitdesigning-people

7. F. Espuelas, El claro en el bosque: reflexiones sobre el vacio en arquitectura (Barcelona: Fundación Caja de Arquitectos, 1999)

8. McGrath, Hsueh, Paul Shan: Rendering the Social, p.1

9. F. Colonnese, Human Figure as a Cultural Mediator in Architectural Drawings. Cultural Influences on Architecture (Hershey, PA: IGI Global, 2016), pp. 110-111

10. H. Melcher, From fireworks to kayaks, step inside the well-produced, world of renderings, https://archpaper.com/2014/07/from-fireworks-to-kayaks-step-inside-thewell-produced-world-of-renderings/

11. F. Colonnese, Collage and Photomontage in 1930s: Piero Bottoni's Architectural Designs. Studies in Visual Arts and Communication, 5, 1

12. V. Iborra Pallarés, I. Capdevila Castellanos, J. L. Oliver Ramírez, Drawing a New Architectural Paradigm. Graphic Imprints. (Cham, Springer, 2018), pp. 274-284

13. J.M. Falcón Meraz, El espacio gráfico habitado: la figura humana en la comunicación visual arquitectónica. Arquiteturarevista, 11, 1 (2015), pp. 36-37

14. Colonnese, Human Figure, pp. 116-117

15. https://www.campobaeza.com/es/conservation-storage-facility-louvre-museum-lievin/

16. Tutti De Sica, exhibition arranged by G. L. Farinelli, Museo dell'Ara Pacis, Roma, 8 febbraio - 28 aprile 2013

17. G. Rosa, L'insegnamento della composizione architettonica (Roma, Officina, 1998) 